\title{
Parameters Investigation of Mathematical Model of Productivity for Automated Line with Availability by DMAIC Methodology
}

\author{
Tan Chan Sin, Ryspek Usubamatov, Mohd Fidzwan B. Md. Amin Hamzas, Low Kin Wai, \\ Teh Keat Yao, and Muhammad Syahril Bahari
}

School of Manufacturing Engineering, Universiti Malaysia Perlis, 02600 Arau, Perlis, Malaysia

Correspondence should be addressed to Tan Chan Sin; tcs5077@gmail.com

Received 17 March 2014; Accepted 10 August 2014; Published 3 November 2014

Academic Editor: Livija Cveticanin

Copyright (c) 2014 Tan Chan Sin et al. This is an open access article distributed under the Creative Commons Attribution License, which permits unrestricted use, distribution, and reproduction in any medium, provided the original work is properly cited.

\begin{abstract}
Automated line is widely applied in industry especially for mass production with less variety product. Productivity is one of the important criteria in automated line as well as industry which directly present the outputs and profits. Forecast of productivity in industry accurately in order to achieve the customer demand and the forecast result is calculated by using mathematical model. Mathematical model of productivity with availability for automated line has been introduced to express the productivity in terms of single level of reliability for stations and mechanisms. Since this mathematical model of productivity with availability cannot achieve close enough productivity compared to actual one due to lack of parameters consideration, the enhancement of mathematical model is required to consider and add the loss parameters that is not considered in current model. This paper presents the investigation parameters of productivity losses investigated by using DMAIC (Define, Measure, Analyze, Improve, and Control) concept and PACE Prioritization Matrix (Priority, Action, Consider, and Eliminate). The investigated parameters are important for further improvement of mathematical model of productivity with availability to develop robust mathematical model of productivity in automated line.
\end{abstract}

\section{Introduction}

Productivity is considered as an important indicator to show the performance in an industry [1]. Since the productivity criteria play an important role in real industry sector, there are several methods or assessments to express or present the productivity. Productivity can be expressed in different phases regarding six ways which are differences of concepts, model variables, calculation order, theoretical framework, accounting technique, and adjustability of the model [2]. From the overview of the research in the productivity area, overall productivity can be categorized into three perspectives which are economic, industrial, and manufacturing perspective.

In the economic perspective, productivity is defined as the ratio of outputs (goods and services) divided by the inputs (resources such as labor and capital) [3]. The definition of productivity is clearly shown in Figure 1.
From Figure 1, the general mathematical model of productivity in economical aspect is

$$
\text { Productivity }=\frac{\text { Output Produced }}{\text { Input Used }} \text {. }
$$

Based on the principal of economy, the primary purpose is underlying the satisfaction of human needs. There are two main activities concerned in productivity which are production and consumption [4]. Production stands for production input and output while consumption is focusing on the usage of manufacturing organization. Productivity in the economic aspect is focusing on few variables which are cost, quality, and quantity.

The second category of productivity is industrial perspective productivity. There is requirement for more assessment in terms of technology criteria when compared to economical productivity which is more focusing on the profit and cost only. Industrial productivity is assessing the performance of 


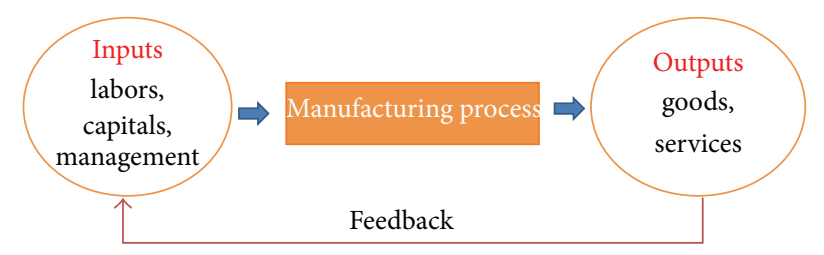

Figure 1: Variable and relationship of economical perspective productivity.

the part of industrial system and one of the most famous methods to measure industrial productivity is overall equipment effectiveness (OEE) [5]. OEE is a quantitative and more reliable approach to assess the current condition of equipment entailed by observing the equipment over a period of time. The mathematical model of OEE is expressed as follows:

$$
\text { OEE }=\text { Availability } \times \text { Efficiency } \times \text { Quality, }
$$

where availability $=$ operation time/net available time, efficiency $=$ theoretical production time/actual production time, and quality $=$ acceptable parts/total part produced.

From the equation model of OEE, it is shown clearly that productivity is based on the availability that reflected the loss of operating time, performance that reflected in net operating time losses, and quality that reflected in value operating time loss. In industrial perspective of productivity, it contains a few specific mathematical models for productivity such as maintenance productivity model.

In manufacturing perspective of productivity, it focuses on the production rate of workstation or transfer line productivity in shop floor. The mathematical model is focusing on the rate of production in workstation or production line. Besides, it focuses on quantity and the time consumed of product. Mathematical models for productivity of workstation are important because they facilitate the evaluation of a manufacturing system on the basis of efficiency. The model in manufacturing can be in terms of manual operated, semiautomated, and fully automated mathematical modeling. Since there is application of fully automated workstation in industries based on the high demands and complexity of products, the mathematical model for fully automated lines and workstations is very important to be discovered. Although there are some mathematical model researches for productivity in manufacturing perspective, one general equation of fully automated workstation or lines is created and shown in the following equation:

$$
\mathrm{Q}=\frac{z}{\theta},
$$

where $Q=$ productivity, $z=$ number of parts produced, and $\theta=$ time used of production.

This mathematical model created and provided the information for productivity in terms of quantity and time spent which produced the result in unit of part/time. This type of mathematical model is showing the production rate in the workstation or transfer line [6]. From the basic mathematical

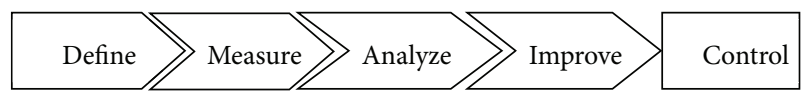

FIGURE 2: DMAIC methodology concept flow for parameters investigation.

model of productivity in perspective of manufacturing, there is a mathematical model of productivity with availability in aspect of average level of reliability which has been developed and the model of serial line with linear action is shown in the following equation [7]:

$$
Q_{\mathrm{a} . \mathrm{r}}=\frac{1}{\left(t_{\mathrm{mo}} / q+t_{a}\right)} \times \frac{1}{1+m_{r}\left[q \lambda_{s}+\lambda_{t}+\lambda_{c}\right]},
$$

where $\mathbb{Q}_{\mathrm{a} . \mathrm{r}}=$ productivity of serial line with average reliability, $t_{\mathrm{mo}}=$ total machining time of a product, $t_{a}=$ auxiliary time to load work pieces in machining area, $q=$ number of stations, $m_{r}=$ mean time to repair, $\lambda_{s}=$ failure rates of workstation, $\lambda_{c}=$ failure rates of the control system in whole line, and $\lambda_{\mathrm{tr}}=$ failure rates of the transport systems in whole line.

The mathematical model of productivity with availability is still not very accurate to express the actual productivity since there are a few parameters of productivity which are not considered in the model. Therefore, the parameters have to be investigated before enhancing the mathematical model of productivity with average reliability to more robust and accurate mathematical model for productivity in automated line.

\section{Methodology}

To investigate the potential parameter of mathematical model of productivity with availability, DMAIC methodology and PACE Prioritization Matrix have been applied for problem solving. DMAIC which stands for Define, Measure, Analyze, Improve, and Control is used to find and solve the problem effectively in six-sigma tool [8-10]. Moreover, PACE Prioritization Matrix is one of the Lean Manufacturing tools which is applied for finding prioritization parameters of productivity for improvement. PACE Prioritization Matrix is applied in the improvement stage of DMAIC for finding the potential parameter to enhance the mathematical model of productivity with average level of reliability and both combinations are considered as Lean-Sigma tools. The overall methodology is starting from definition of the problems to the improvement of parameter and is followed by final parameters which are required to be considered and improved for a more accurate model which is shown in Figure 2.

2.1. Define. The mathematical model of productivity in automated line with availability of productivity is required to state and define the main problem of the model. Both the equations of productivity which are categorized as actual productivity and average level of reliability productivity model have to be stated to show the differentiation. 
2.2. Measure. Both equations are measured by using the working example of result and by the comparison between the average levels of reliability productivity result and the actual productivity result. Equations (3) and (4) are applied for calculation to show the deviation of productivity model with average reliability result with actual result.

2.3. Analyze. The purpose is to analyze the differentiation of mathematical model of productivity with availability to the actual productivity. Losses diagram of productivity is applied to find the level of loss of productivity [11]. By using this diagram, the parameters that are ignored or not considered in mathematical model of productivity with average level of reliability will be seen clearly.

2.4. Improve. Since there are many parameters which can be considered to enhance the mathematical model of productivity with availability, PACE Prioritization Matrix is used to manage the priority to focus on high impact parameters and more easier to express in terms of mathematic equation. PACE is decided by a close group who is related to and experienced in the problems and conditions. The parameters that obtained from analyze stage are put into different categorizes of PACE which are Prioritization (high priority and high impact parameter), Action (small effort with moderate impact parameter), Challenge (high impact but high difficulties), and Eliminate (small impact with high difficulties) [12]. The categories of Prioritization and Action are considered as potential parameters for mathematical model of productivity enhancement.

2.5. Control. In conjunction with the mathematical model of productivity and average level of reliability losses parameter problem, the control stage is to obtain the potential parameter from improvement stage and confirm the potential parameters for further mathematical model improvement.

\section{Results and Discussions}

Data collection is done in a motorcycle production company which is applying automated line in final assembly line department. The data apply to methodology above to determine the result for this research that is shown in Tables 1 to 4 . Actual data from Table 3 is taken from yield of motorcycle production automated line while Tables 1 and 2 are the technical data and reliability data from the same line. Result is presented clearly with five sections and is shown as below.

3.1. Define. From the view of original productivity, the simple model of productivity is ratio of output to input. Since the requirement of industrial productivity should be more on technical parameters such as number of part and time, the actual productivity is derived in (3).

The improvement of the general equation of productivity with theory of reliability has been created which is expanding of basic equation of productivity. The mathematical model of productivity with average reliability in serial line is shown in (4).
TABLE 1: Technical data of a serial automated line.

\begin{tabular}{lc}
\hline Title & Data \\
\hline Total machining time, $t_{\mathrm{mo}},(\mathrm{min})$ & 35 \\
Auxiliary time, $t_{a},(\mathrm{~min})$ & 0.3 \\
Number of stations, $q$ & $5-25$ \\
\hline
\end{tabular}

TABLE 2: Reliability indices of the automated line.

\begin{tabular}{lcc}
\hline Title & $q$ & $\lambda_{\text {s.i }}($ failures/min $)$ \\
\hline & $1-5$ & $7.0 * 10^{-2}$ \\
& $6-10$ & $5.0 * 10^{-2}$ \\
& $11-15$ & $8.0 * 10^{-2}$ \\
Failure rate of the stations $q, \lambda_{s}$ & $16-20$ & $6.0 * 10^{-2}$ \\
& $21-25$ & $9.0 * 10^{-2}$ \\
& $26-30$ & $7.0 * 10^{-2}$ \\
& Average & $7.0 * 10^{-2}$ \\
\hline Failure rate of the control system, $\lambda_{c}$ & & $8.0 * 10^{-4}$ \\
\hline Failure rate of the transport system, $\lambda_{\text {tr }}$ & & $4.0 * 10^{-5}$ \\
\hline Mean repair time, $m_{r}$ & $3.0 \mathrm{~min}$ \\
\hline
\end{tabular}

3.2. Measure. By comparing the equation above with the actual productivity, there is a set of technical data which is based on the literature review that will be applied on both equations to recognise the accuracy of mathematical model of productivity with availability compared to the actual productivity. The technical data and reliability indices are shown in Tables 1-4.

By setting the total time of processing maintained, the total processing time is equal to cycle time and the actual productivity can be measured and calculated by using (3) and the result is shown in Table 3. Besides, the total processing time shown in Table 3 is calculated by using the following equation:

$$
\theta=T=t_{\mathrm{mo}}+t_{a}=35 \mathrm{~min}+0.3 \mathrm{~min}=35.3 \mathrm{~min} .
$$

After calculating and measuring the actual productivity, the substitution of the data in Tables 1 and 2 into (4) which is mathematical model of productivity in average. By comparing both results of productivity, actual productivity model and model of productivity with availability are shown in Table 4 and Figure 3.

3.3. Analyze. By comparing the actual productivity and mathematical model of productivity with the availability of station in automated line, the result shows that the productivity is higher but not very close to the actual result. This means that the result of calculation of productivity with single reliability is higher when compared to actual result. Since that, the importance of mathematical model of productivity in automated line is to forecast the productivity accurately, so the mathematical model of productivity with availability must be improved. By observing both results of productivity, the actual productivity is lesser than the mathematical model of productivity result because there are a few parameters that cause losses of productivity which is not considered in the mathematical model of productivity with availability. 
TABLE 3: Actual productivity calculation.

\begin{tabular}{lcccccc}
\hline Number of stations, $q$ & 5 & 10 & 15 & 20 & 25 & 30 \\
Number of products, $z$ (prod) & 2 & 2.8 & 2.9 & 3 & 2.8 & 2.7 \\
Total processing time, $\theta$ (min) & 35.3 & 35.3 & 35.3 & 35.3 & 35.3 & 35.3 \\
$Q_{\mathrm{ac}}$ (prod/min) & 0.057 & 0.079 & 0.082 & 0.085 & 0.079 & 0.077 \\
\hline
\end{tabular}

TABLE 4: Comparison of mathematical model of productivity with actual productivity.

\begin{tabular}{lcccccc}
\hline Number of stations, $q$ & 5 & 10 & 15 & 20 & 30 \\
$Q_{\mathrm{ac}}(\mathrm{prod} / \mathrm{min})$ & 0.057 & 0.079 & 0.082 & 0.085 & 0.079 & 0.077 \\
$Q_{\mathrm{a} . \mathrm{r}}(\mathrm{prod} / \mathrm{min})$ & 0.067 & 0.084 & 0.091 & 0.093 & 0.094 & 0.093 \\
\hline
\end{tabular}

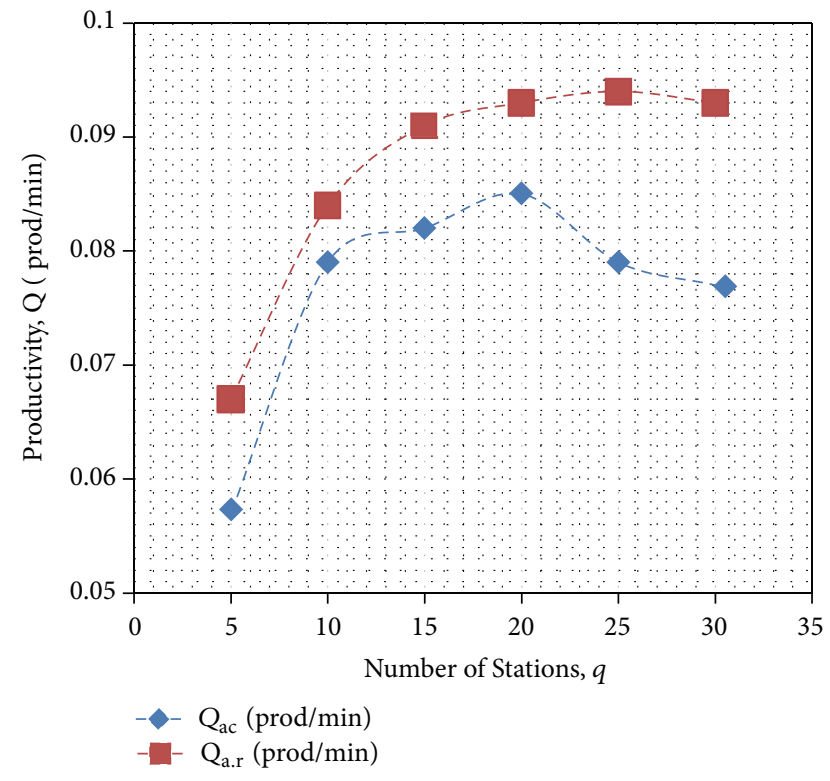

FIGURE 3: Graph of actual productivity $\left(Q_{a c}\right)$ with average reliability productivity $\left(Q_{\mathrm{a} . \mathrm{r}}\right)$.

Table 5 presents the parameters that are not considered in the mathematical model of productivity with availability through literature review.

From the parameters that are not considered in mathematical model of productivity with availability, the further analysis of parameters for improvement is presented via Losses Productivity Diagram. The losses of parameters in mathematical model of productivity in the actual condition can be performed in the Losses Productivity Diagram which is shown in Figure 4.

Regarding the analysis diagram of productivity losses in Figure 4, there are few types of productivity which are based on the losses level in automated line. The relationship between productivity and time used shows that when time used in production increases, the productivity of production is decreased or vice versa. Productivity is inversely proportional to production time. Potential productivity $(K)$ is also called technological productivity where there is pure machining time spent and no other auxiliary or idle time $\left(K=1 / t_{m}\right)$. This is the perfect or ideal productivity in

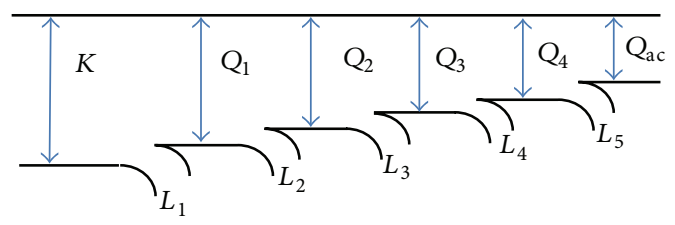

FIGURE 4: Productivity losses analysis for mathematical model of productivity with availability. $K=$ potential productivity $\left(1 / t_{m}\right), Q_{1}$ = cyclic productivity $\left(1 / t_{m}+t_{a}\right), Q_{2}=$ productivity of bottleneck machining time, $Q_{3}=$ productivity of average level reliability for stations and mechanisms, $Q_{4}=$ productivity and different level reliability of stations and mechanisms, $Q_{\mathrm{ac}}=$ actual productivity, $L_{1}$ = productivity losses of auxiliary time, $L_{2}=$ productivity losses of bottleneck of machining time of stations, $L_{3}=$ productivity losses of average reliability of stations and mechanisms, $L_{4}=$ productivity losses of different reliability of stations and mechanisms, and $L_{5}$ $=$ productivity losses of managerial problem and rejected/defected parts.

automated line since there is no any idle and auxiliary time and this potential productivity cannot be realized in real condition of company since there must be some losses of time during production. $Q_{1}$ which is cyclic productivity that represents the automated line productivity considers the losses of machining time and auxiliary time but no other idle or down time included. However, in the reality of automated line in industry, there are some idle times that occurred such as maintenance and breakdown. Cyclic productivity is expressed as $Q_{1}=1 / t_{m}+t_{a},\left(Q_{1}=\right.$ Cyclic Productivity, $t_{m}=$ Machining Time, $t_{a}=$ Auxiliary Time). Bottleneck of workstation is another reason which causes the loss of productivity because the bottleneck of machining time for one workstation will cause the delay of production time. In automated line, the flow of production is continuous and connected production. When the production time of automated line is delayed by one bottleneck workstation, the whole automated line is affected. $Q_{2}$ is the productivity with losses of bottleneck station $\left(L_{2}\right)$.

The next level of productivity is average reliability of station and mechanism $\left(Q_{3}\right)$ which included the loss of machining time, auxiliary time, and idle time regarding the average level of calculation of loss of time in workstation or mechanism with the theory of reliability. The losses of average reliability are stated in terms of $L_{3}$. Since the level of reliability of each workstation and mechanism is different, 
TABLE 5: Summary of potential parameters to enhance current productivity model.

\begin{tabular}{|c|c|c|c|c|}
\hline Number & Potential parameters & Explanations of parameter & Frequent & Citation \\
\hline 1 & Defected parts & $\begin{array}{l}\text { Defected parts happen in every } \\
\text { production line and this will affect and } \\
\text { decrease the actual productivity }\end{array}$ & $\begin{array}{l}\text { Frequently happen in } \\
\text { all production line }\end{array}$ & {$[13-15]$} \\
\hline 2 & $\begin{array}{l}\text { Different reliability of } \\
\text { working stations and } \\
\text { mechanism }\end{array}$ & $\begin{array}{l}\text { Each of the working stations and } \\
\text { mechanisms has its own reliability which } \\
\text { is different from each other and this will } \\
\text { affect the final productivity }\end{array}$ & $\begin{array}{l}\text { Frequently happen in } \\
\text { all production line }\end{array}$ & [16-18] \\
\hline 3 & $\begin{array}{c}\text { Machining bottleneck } \\
\text { time }\end{array}$ & $\begin{array}{l}\text { Difference of machining time happens in } \\
\text { the all serial line and there will be a } \\
\text { station which has higher machining time } \\
\text { which is considered bottleneck }\end{array}$ & $\begin{array}{l}\text { Frequently happen in } \\
\text { serial action } \\
\text { production line }\end{array}$ & {$[19,20]$} \\
\hline 4 & $\begin{array}{c}\text { Time losses of } \\
\text { managerial problems }\end{array}$ & $\begin{array}{l}\text { Time losses due to managerial problem } \\
\text { such as planning error will slightly affect } \\
\text { the final productivity }\end{array}$ & $\begin{array}{l}\text { Minor happen in } \\
\text { production line due to } \\
\text { avoidable parameter }\end{array}$ & {$[6]$} \\
\hline
\end{tabular}

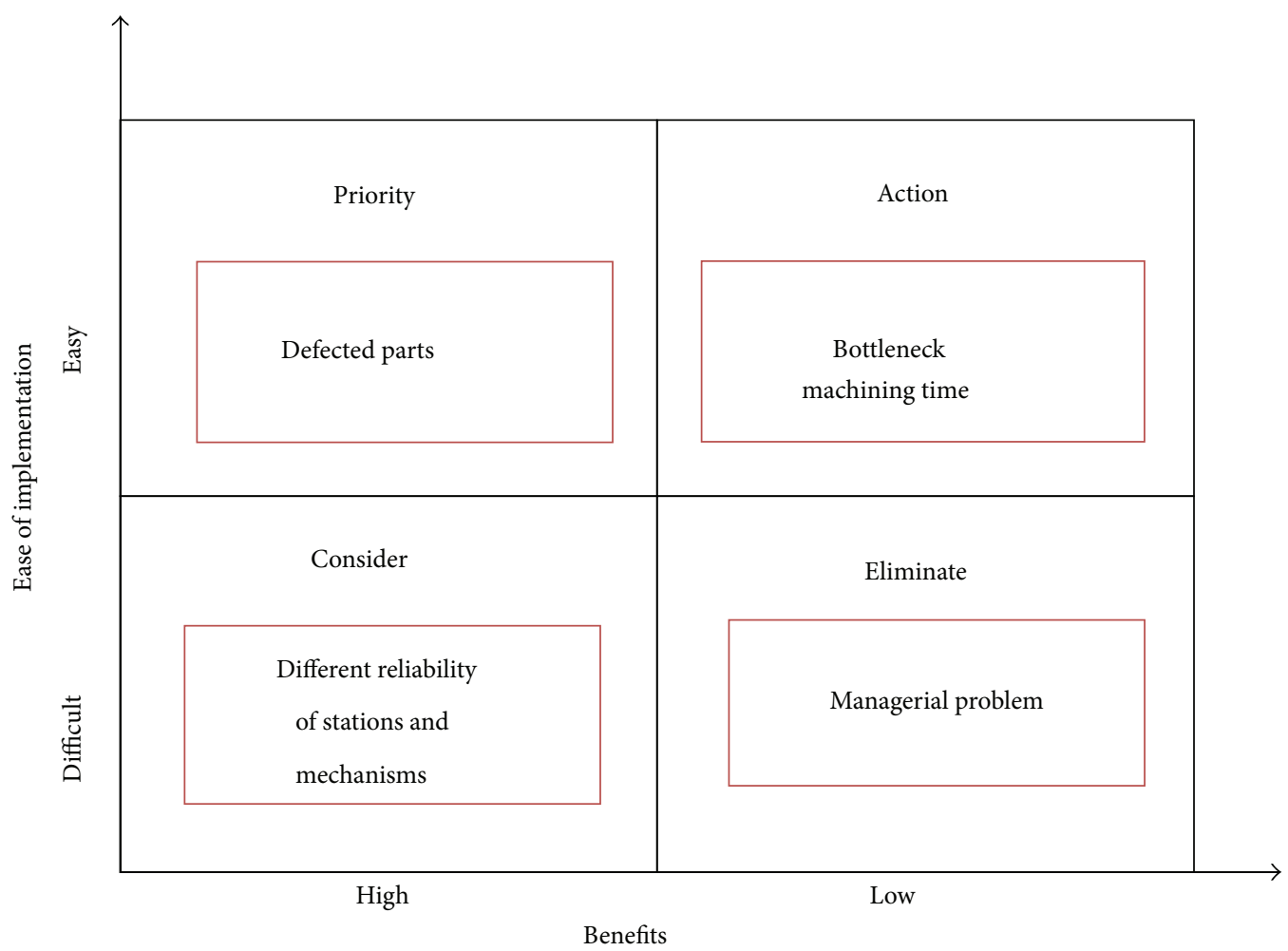

FIGURE 5: PACE Prioritization Matrix of parameters of mathematical model of productivity.

the different levels of each workstation and mechanism have to be considered for obtaining the closer result of actual productivity and the productivity is $Q_{4}$ which is different level of reliability for station and mechanism with the losses of $L_{4}$.

Another reason that causes losses of productivity is managerial problems and rejected or defected parts $\left(L_{5}\right)$. Actual productivity $\left(Q_{\mathrm{ac}}\right)$ is obtained after the determination of losses of managerial problems and rejected part. Managerial problems such as material planning problems will affect the time losses of production while rejected or defected parts will decrease the finished good output of automated production line. After defining the losses level of productivity in automated line, the final result affects the actual productivity which is the real condition product divided by actual time spent.

3.4. Improve. The parameters obtained from analysis, which are different level of reliability of station and mechanisms, bottleneck time of station, rejected parts, and managerial problems, will be categorized into four matrices. The obtained parameters are categorized into four groups of PACE through a discussion of closed group. The closed group consists of five people which is the productivity of automated line theory research team that included process engineers and productivity researchers. The result of discussion is categorized and shown in Figure 5. 
From the analysis of PACE Prioritization Matrix in Figure 5, the defected parts are put in the first prioritization to solve since it gives high impact to the output calculation and can solve by mathematical solution. The second prioritization parameter is different level of reliability of stations and mechanism in workstation because it has high impact on mathematical model but requires more complex mathematical solution to solve when compared to defected parts parameters. Since bottleneck of machining time is easy but less impact than defected part and different reliability, it can still be solved by mathematical express so that this parameter is considered potential parameter. For managerial problems, it is less impact to the productivity result and the due to unexpected of happen is cause to difficulty to express in mathematic form. Since the parameter obtained should be expressed in mathematical model, the parameters that focus on improving and enhancing the mathematical model of productivity with availability are defected parts, different level of reliability, and bottleneck time of machining which are used to apply and enhance the mathematical model.

3.5. Control. After the stages of define, measure, analyze, and improve, the final potential parameters which included defected parts, different level of reliability, and bottleneck time of machining are considered in future development for more robust and accurate mathematical model of productivity in automated lines.

\section{Conclusion}

The use of mathematical model of productivity in automated line for problem solving and for productivity forecasting becomes common. A robust and accurate model of productivity should be developed. By referring to the result obtained from this research paper, the high potential parameters that are not included in mathematical model of productivity of average level of reliability are defected parts, different level of reliability, and bottleneck time of machining. By applying these two parameters to mathematical model of productivity, the new and robust mathematical model of productivity can be developed in further research.

\section{Conflict of Interests}

The authors declare that there is no conflict of interests regarding the publication of this paper.

\section{Acknowledgments}

Tan Chan Sin would like to thank his Ph.D. supervisor, Professor Ryspek Usubamatov, for giving him a lot of guidance for his research. Furthermore, he would also like to express his appreciation to his research partners, Fidzwan, Low, and Teh, who always help in solving some technical problems.

\section{References}

[1] G. Chryssolouris, Manufacturing Systems: Theory and Practice, Springer, New York, NY, USA, 2nd edition, 2010.

[2] S. Saari, "Theory and measurement in business," in Proceedings of the Espoo European Productivity Conference, pp. 1-10, Espoo, Finland, 2006.

[3] J. Heizer and B. Render, Operations Management, Pearson Education, Upper Saddle River, NJ, USA, 2006.

[4] S. Saari, Production and Productivity as Sources of Well-Being, Mido Oy, Esbo, Finland, 2011.

[5] S. H. Huang, J. P. Dismukes, J. Shi et al., "Manufacturing system modeling for productivity improvement," Journal of Manufacturing Systems, vol. 21, no. 6, pp. 249-259, 2002.

[6] L. Volchkevich, Automation of Manufacturing Processes, Mashinostroenie, Moscow, Russia, 2005.

[7] R. Usubamatov, K. A. Ismail, and J. M. Sah, "Mathematical models for productivity and availability of automated lines," International Journal of Advanced Manufacturing Technology, vol. 66, no. 1-4, pp. 59-69, 2013.

[8] J. de Mast and J. Lokkerbol, "An analysis of the Six Sigma DMAIC method from the perspective of problem solving," International Journal of Production Economics, vol. 139, no. 2, pp. 604-614, 2012.

[9] C. L. Leaphart, T. A. Gonwa, M. L. Mai et al., "Formal quality improvement curriculum and DMAIC method results in interdisciplinary collaboration and process improvement in renal transplant patients," Journal of Surgical Research, vol. 177, no. 1, pp. 7-13, 2012.

[10] P. Mandal, "Improving process improvement: executing the analyze and improve phases of DMAIC better," International Journal of Lean Six Sigma, vol. 3, no. 3, pp. 231-250, 2012.

[11] R. U. Abdul Rahman Riza, "Methodology development for calculating productivity and its loss to measure productivity incremental in assembly line environment," in Proceedings of the International Conference on Plant Equipment and Reliability (ICPER '08), pp. 94-98, 2008.

[12] G. S. Kaplan, "Value stream mapping-PACE matrix", in Advanced Lean Thinking: Proven Methods to Reduce Waste and Improve Quality in Health Care, H. M. Fry, Ed., p. 29, Joint Comission Resource, 2008.

[13] Z. Wen and Y. Tao, "Building a rule-based machine-vision system for defect inspection on apple sorting and packing lines," Expert Systems with Applications, vol. 16, no. 3, pp. 307-313, 1999.

[14] H. Y. T. Ngan, G. K. H. Pang, and N. H. C. Yung, "Automated fabric defect detection - a review," Image and Vision Computing, vol. 29, no. 7, pp. 442-458, 2011.

[15] A. Pagnano, M. Höpf, and R. Teti, "A roadmap for automated power line inspection," Procedia CIRP, vol. 12, pp. 234-239, 2013.

[16] K. Das, "A comparative study of exponential distribution vs Weibull distribution in machine reliability analysis in a CMS design," Computers and Industrial Engineering, vol. 54, no. 1, pp. 12-33, 2008.

[17] S. Ghosh and S. K. Majumdar, "Reliability modeling and prediction using classical and Bayesian approach: a case study," International Journal of Quality and Reliability Management, vol. 28, no. 5, pp. 556-586, 2011.

[18] Z.-M. Wang and J.-G. Yang, "Numerical method for Weibull generalized renewal process and its applications in reliability analysis of NC machine tools," Computers and Industrial Engineering, vol. 63, no. 4, pp. 1128-1134, 2012. 
[19] A. D. Neely and M. D. Byrne, "A simulation study of bottleneck scheduling," International Journal of Production Economics, vol. 26, no. 1-3, pp. 187-192, 1992.

[20] A. Ingemansson, T. Ylipää, and G. S. Bolmsjö, "Reducing bottlenecks in a manufacturing system with automatic data collection and discrete-event simulation," Journal of Manufacturing Technology Management, vol. 16, no. 6, pp. 615-628, 2005. 


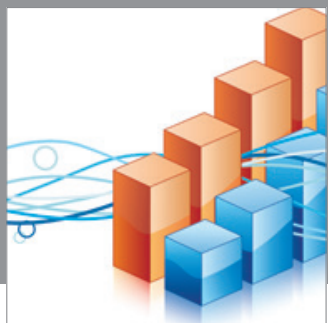

Advances in

Operations Research

mansans

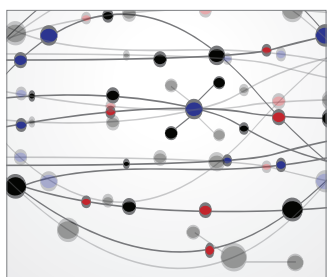

The Scientific World Journal
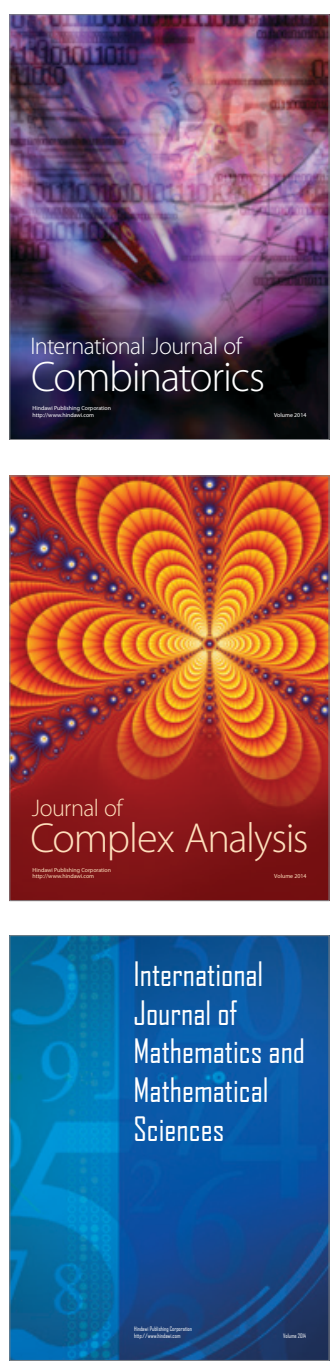
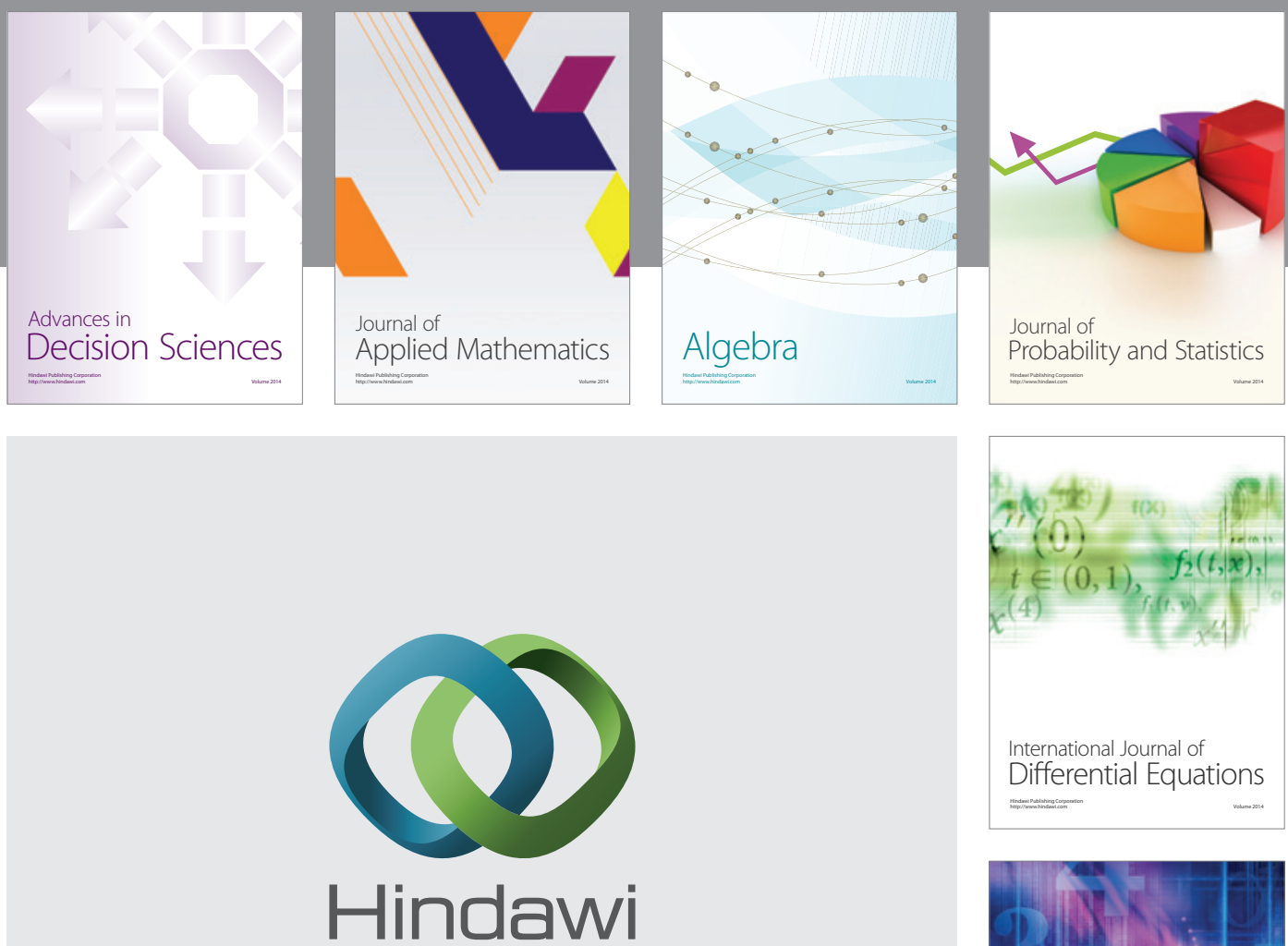

Submit your manuscripts at http://www.hindawi.com
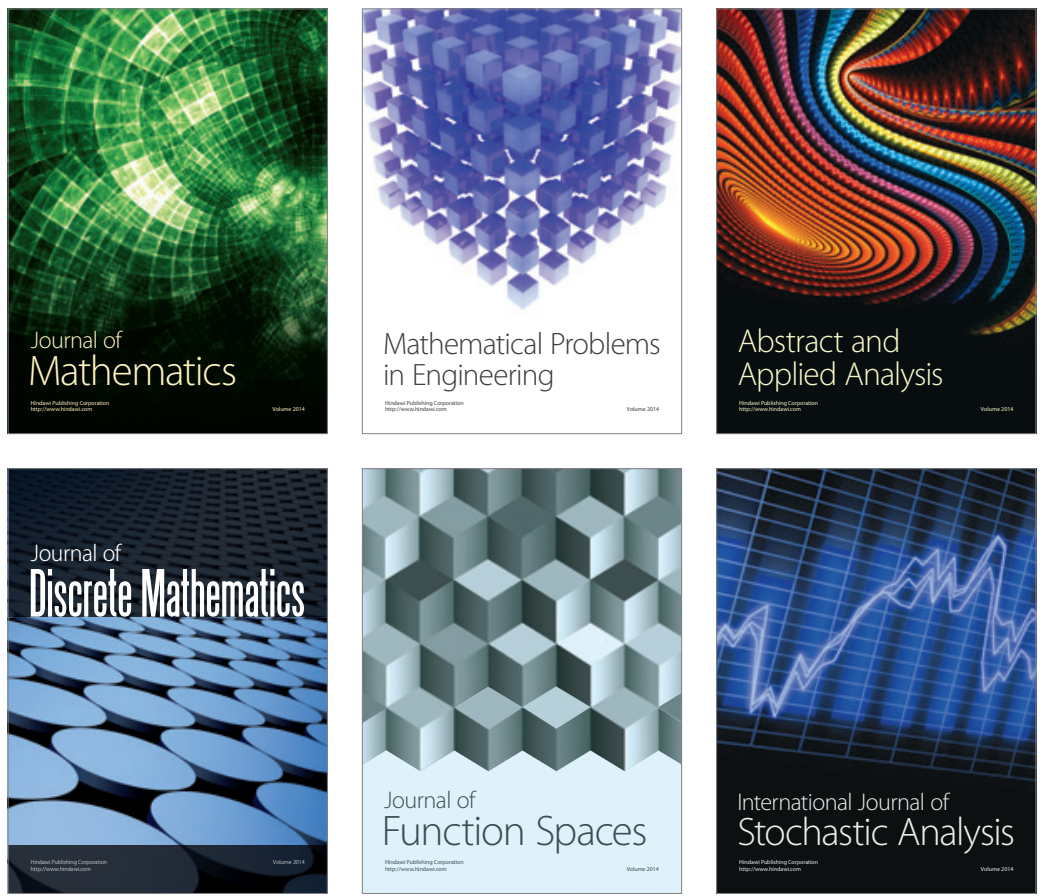

Journal of

Function Spaces

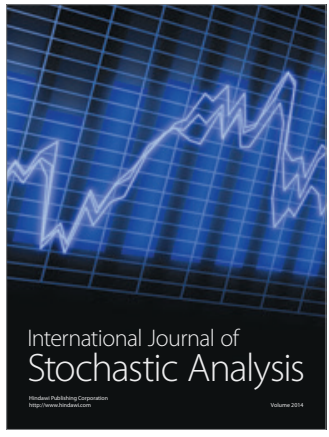

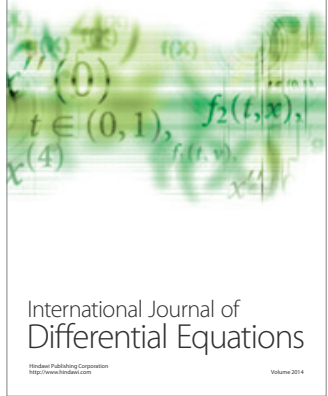
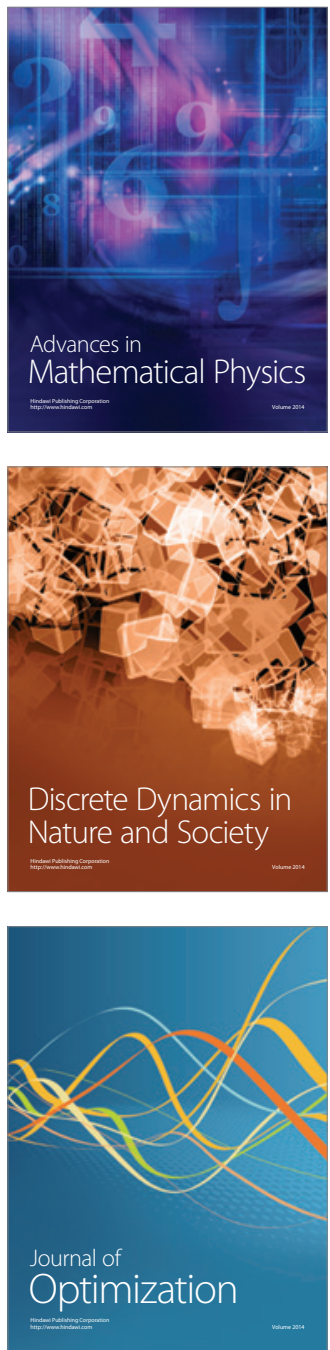